\title{
Comparing the effects of minimal handling protocols on the physiological parameters of preterm infants receiving exogenous surfactant therapy
}

\author{
Laura A. Cabral ${ }^{1}$, Marcelo Velloso ${ }^{2}$
}

\begin{abstract}
Background: The practice of minimal handling is recommended for preterm infants (PTIs). However, few studies have investigated the effects of this practice among these infants or the time needed to ensure greater physiological stability, especially after exogenous surfactant treatments. Objective: The current study compared the effects of two protocols of minimal handling on the physiological variables of PTIs after surfactant therapy. Method: An exploratory prospective observational study was performed with 40 PTIs weighing less than $1,500 \mathrm{~g}$. The infants were divided into two groups and monitored for 72 hours. One group received the standard minimal handling procedure during the first 12 hours after surfactant therapy; the other group (i.e., the modified group) received minimal handling within 72 hours after surfactant therapy. Infant heart rate (HR), oxygen saturation, body temperature, and the adverse events associated with changes to these variables were monitored every 10 minutes. Results: Significant between-group differences were not found with regard to the occurrence of the adverse events associated with physiological changes ( $p>0.05)$. Conclusion: The practice of minimal handling among very low birth weight infants did not alter their physiological stability when performed either 12 or 72 hours after surfactant therapy.
\end{abstract}

Keywords: physiology; physical therapy; premature infants; pulmonary surfactants; neonatal intensive care.

\section{HOW TO CITE THIS ARTICLE}

Cabral LA, Velloso M. Comparing the effects of minimal handling protocols on the physiological parameters of preterm infants receiving exogenous surfactant therapy. Braz J Phys Ther. 2014 Mar-Apr; 18(2):152-164. http://dx.doi.org/10.1590/ S1413-35552012005000154

\section{Introduction}

Advances in the health area and neonatal intensive care have led to increased survival rates among lowbirth-weight preterm infants (PTIs) ${ }^{1-3}$. Prematurity is an important indicator of health because it affects aspects of development and growth throughout childhood $^{3}$. Recently, changes in the profile and survival rates of PTIs, especially those with very low birth weights, have led to modifications in the antenatal and postnatal care provided to them ${ }^{1,4,5}$. With regard to postnatal care, exogenous surfactant therapy ${ }^{6,7}$ and developmental care centered on the newborns (NBs) and their families ${ }^{8,9}$ are of particular relevance.

Exogenous surfactant replacement therapy significantly improves oxygenation, which can reduce time on mechanical ventilation (MV), oxygen use, length of hospital stay, and the mortality rate among PTIs ${ }^{6,7}$. However, evidence shows that this therapy is associated with adverse events such as acute episodes of decreased peripheral oxygen saturation, bradycardia, pulmonary hemorrhage, and systemic hypotension, all of which can lead to changes in cerebral blood flow and the risk of periintraventricular hemorrhage (PIVH) ${ }^{10}$.

Developmental care routines such as minimal handling procedures, PTI rest period maximization, and the distribution of group care over 24-hour periods $^{8,9}$ require reduced sound and light levels in neonatal intensive care units (NICUs). In this manner, health professionals who care for these infants are "coregulators" and should provide adequate support for the $\mathrm{NBs}^{11}$. Contact between children admitted to the NICU and their parents should be encouraged because it allows a bond to form and provides comfort 
to the family ${ }^{12,13}$. These types of care have improved developmental outcomes, reduced the number of days on MV, decreased the incidence of PIVH, and improved the autonomic stability and self-regulation abilities of PTIs 9 .

Very low birth weight $(<1,500 \mathrm{~g})$ PTIs diagnosed with respiratory distress syndrome (RDS) due to hyaline membrane disease (HMD) and needs the MV there are greater risk for developing PIVH over the first three days (72 hours) of life $\mathrm{e}^{14}$. This period is critical because these NBs there are possibilites to changes in cardiovascular parameters due to the immaturity of the central nervous system, in addition to frequent handlings resulting from of the various routine procedures in intensive care units ${ }^{15}$.

Although minimal handling is recommended for PTIs ${ }^{16}$, few studies have evaluated the effects of this practice on NBs or the time needed to ensure their general physiological stability. Given the potential risks and adverse events associated with exogenous surfactant therapy as well as the risk of developing PIVH over the first 72 hours of life among very low birth weight NBs, this study was conducted to compare the effects of two minimal handling protocols on physiological variables in very low birth weight infants on MV over the first 72 hours after surfactant therapy.

\section{- Method}

This exploratory, prospective, and observational study was conducted in a neonatal intensive care center that continuously monitored the dependent variables as well as counted the number and type of procedures performed and the number of adverse events that occurred among two groups of PTIs receiving different minimal handling protocols (i.e., the standard group [SG] and the modified group [MG]; Appendix 1) for 72 hours after exogenous surfactant therapy. The first 12 hours after surfactant therapy were considered the baseline period during which all NBs participating in the study received similar handling conditions. The participants were selected using the following inclusion criteria: The mother, father, or guardian signed an informed consent document; NB birth weight $<1,500 \mathrm{~g}$; endotracheal intubation and invasive MV at birth; and exogenous surfactant therapy via an endotracheal tube ${ }^{17}$. NBs were excluded due to severe bradycardia (heart rate $[\mathrm{HR}]<60 \mathrm{bpm}$ ) or spontaneous severe desaturation (peripheral oxygen saturation $\left[\mathrm{SpO}_{2}\right]<60 \%$ ) shortly after birth, requiring cardiac massage or ventilation with a manual resuscitator; pneumothorax or the use of thoracic drainage, pulmonary hemorrhage or death, severe neurological disorders, severe congenital abnormalities, or extubation less than 72 hours after surfactant therapy.

The approximate sample size (n) for this study was obtained using 16 PTIs from a pilot study and an estimation using Student's $t$-test for independent samples with a maximum allowable difference of one unit, a power of 0.80 , and the greatest standard deviation among the dependent variables (i.e., $\mathrm{SpO}_{2}=1.76$ ). This measure was estimated between groups, and $\mathrm{SpO}_{2}$ was considered to be the primary outcome. The minimum expected difference for the groups was a desaturation value of $2 \%$ below the lower limit (85\%), which was considered to characterize an adverse event associated with this variable after 12 hours of surfactant therapy administration (values between $85 \%$ and $88 \%$ were disregarded because they might represent the intrinsic measurement variability of the device itself). This study estimated that an $\mathrm{n}$ of 50 PTIs was required for each group, for a total $\mathrm{n}$ of 100 .

A sample of 78 PTIs was recruited during the study (36 in the SG and 40 in the MG). However, 36 PTIs (14 in the SG and 22 in the MG) were excluded due to the occurrence of at least one exclusion criterion (Figure 1). The data of two other PTIs were excluded due to experimenter error. Therefore, the final sample consisted of 40 PTIs (22 in the SG and 18 in the MG). Statistical power was calculated using Student's $t$-test approximation, yielding a power of 0.99 after considering a difference of one standard deviation among the number of adverse events for each variable, per group.

Physiological effects were evaluated. HR and $\mathrm{SpO}_{2}$ (with a pulse oximeter) were continuously monitored and recorded automatically using a Model 2023 Dixtal $^{\circledR}$ monitor (Manaus-AM, Brazil, precalibrated) with data stored for later analysis. Axillary temperature was recorded using an Incoterm $^{\circledR}$ mercury thermometer (Wuxi Medical Instrument Factory, Jiangsu, China; national representative: Incoterm Industry Thermometers Ltd., Porto Alegre, RS, Brazil).

The $\mathrm{HR}$ and $\mathrm{SpO}_{2}$ data were recorded at ten-minute intervals per monitored evolution and analyzed 72 hours after exogenous surfactant therapy by a study collaborator. 
HR was monitored continuously and noninvasively, and values between 90 and $180 \mathrm{bpm}$ were used for data analysis. Adverse bradycardia events were considered for values below 90, and adverse tachycardia events were considered for values above $180^{18}$. Importantly, the electrocardiogram was not thoroughly evaluated.

$\mathrm{SpO}_{2}$ was monitored continuously and noninvasively using a pulse oximeter with a "Y" sensor located on the NBs' toes or thumbs (postductal); $\mathrm{SpO}_{2}$ values between $85 \%$ and $95 \%$ were used for data analysis. Adverse events were considered for values below $85 \%$ desaturation ${ }^{17}$.

The nursing technician responsible for the NB noninvasively monitored infant axillary temperature every two hours using an Incoterm ${ }^{\circledR}$ mercury thermometer; axillary temperature values between 36.5 and $37.5^{\circ} \mathrm{C}^{18}$ were considered normal for data analyses. Values below 36.5 were considered adverse hypothermia events, and those above 37.5 were considered adverse hyperthermia events.
The transfontanelle ultrasound test results (performed 72 hours after birth as a routine institutional examination) were recorded on the data collection form for each participant. The Nemio XG (Thoshiba, Tokyo, Japan) was used for this test. Frequency analyses of the presence of $\mathrm{PIVH}^{19}$ among the study group and between-group difference comparisons were performed. The professional responsible for the execution of this examination was blinded to group assignment.

The PTIs were divided into two groups: Those in the SG received the institution's existing minimal handling protocol during the first 12 hours after surfactant therapy; those in the MG received the minimal handling protocol during the first 72 hours after surfactant therapy (i.e., the standard 12-hour protocol plus 60 hours after surfactant therapy). A blue (SG) or red (MG) identifying plate was placed on the incubator of each participant. This identification remained on the incubator throughout

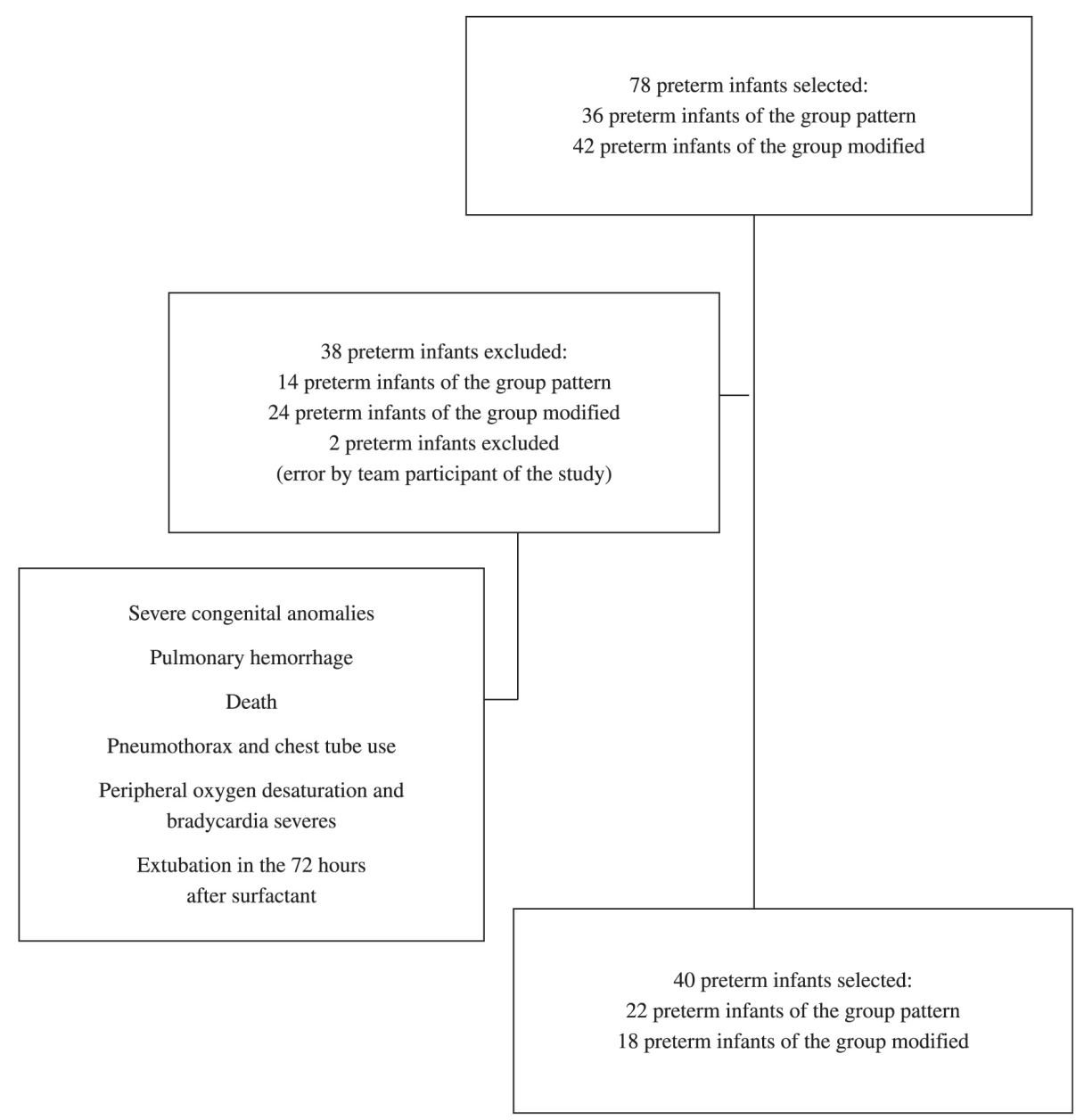

Figure 1. Procedure of sample selection. 
the study period. Minimal handling time was used to differentiate the study protocols.

The PTIs in both groups remained in the supine position with a headboard inclined at 30 degrees. The PTIs did not change position for 12 hours after surfactant therapy, and they received the multidisciplinary team care procedures based on their needs according to the minimal handling protocol of the institution where the study took place. Twelve hours after surfactant therapy, the SG PTIs received routine care procedures until 72 hours after surfactant therapy according to the neonatal intensive care routine of the institution where the study took place. The MG PTIs remained supine with a headboard inclined at 30 degrees. The PTIs did not change positions for 72 hours after surfactant therapy and received the multidisciplinary team care procedures based on their needs.

All participants underwent 19 procedures. The invasive procedures included venous, capillary, arterial (performed by the nursing team, physicians team, or both), and lumbar (physicians team) punctures, peripheral access, passage of indwelling urinary and gastric catheters (nursing team), suction, and the repositioning of the endotracheal tube (physical therapy team). Evaluation (i.e., noninvasive) procedures were performed by all teams, including changing diapers, bed sheets, positions, and sensors as well as perianal swabs, dressing changes (nursing team), radiography (radiographer), adjusting MV (physicians team, physical therapy team, or both), and replacement the fixation of the endotracheal tube (physical therapy team).

The team of professionals who conducted the protocols was composed of pediatricians, nurses, nursing technicians, and physical therapists. The primary researcher trained these professionals with regard to the present study's protocols before the study began. This training was conducted over one month during all shifts (morning, afternoon, and night) for 30 to 40 minutes, either individually or in pairs. A total of 137 professionals (all members of the multidisciplinary team) were trained (Appendix 2).

A fabric covered all PTI incubators to dim the lights in the NICU. Infants undergoing phototherapy wore eye protectors, and the incubators in which they were placed were partially covered with fabric.

The present study was performed in accordance with Resolution 196/96 of the National Health Council of Brazil (Conselho Nacional de Saúde do Brasil); Ethics Committee Protocols: 0606.0.203.000-09 of the Universidade Federal de Minas Gerais (UFMG), Belo Horizonte, MG, Brazil and Resolution 10/2009 of the Sofia Feldman, Belo Horizonte, MG, Brazil. The parents and guardians of the participants were informed of the study protocols, which were only performed after they had read and signed the informed consent document.

\section{Statistical analysis}

Data analyses were performed using descriptive techniques to identify adverse events and major PTI characteristics. An analysis of the relationship between the categorical variables and the minimal handling protocols was performed using Fisher's exact test. The nonparametric Mann-Whitney test was used to examine continuous, quantitative variables. A correlational analysis of the number and types of procedures and adverse events was performed using Spearman's test.

These tests were used because of the small sample size and because their efficiency is similar to those of parametric tests. The significance threshold used in this study was $5 \%$.

The analyses were performed using Statistical Package For Social Sciences (SPSS, Chicago, IL, USA), version 13.0.

\section{Results}

Table 1 shows the PTI characteristics by gestational age, birth weight, and their 1- and 5-minute Apgar scores. Table 2 shows the distribution of participants by gender, size according to gestational age, the use of antenatal corticosteroids, and their HMD classification. The participants are divided into groups (SG and MG) in both tables.

Table 3 shows that the adverse events evaluated during the first 12 hours (SG) and between 12 and 72 hours (MG) after surfactant therapy were similar (i.e., significant difference were not observed between them; $\mathrm{p}>0.05$ ).

A significant between-group difference was observed with regard to the occurrence of PIVH: All NBs who presented PIVH $(n=6)$ were assigned to the SG ( $\mathrm{p}=0.02)$. Specifically, $4 \mathrm{NBs}$ had grade I (one to the right, two to the left, one bilateral), and 2 NBs had bilateral grade III.

The mean number of procedures per PTI was 72.7 (8.4). The variation coefficient shows that the variability near the mean was $11.5 \%$, which is low. No between-group differences were observed 
with regard to this parameter $(\mathrm{p}=0.26)$. Significant group differences were observed with regard to noninvasive $(\mathrm{p}=0.02)$ and nursing procedures $(\mathrm{p}=0.01)$; specifically, the SG underwent more of these types of procedures.

Significant between-group differences were not observed with regard to invasive $(\mathrm{p}=0.10)$ and physicians procedures $(\mathrm{p}=0.10)$. However, physicians $(\mathrm{r}=0.48, \mathrm{p}=0.002)$, generally invasive $(\mathrm{r}=0.46, \mathrm{p}=0.003)$, and physical therapy procedures (specifically endotracheal tube suction, $r=0.67$, $\mathrm{p}<0.001)$ showed weak to moderate correlations with desaturation events regardless of PTI group (Figure 2).

Importantly, the characteristics related to the medical treatment of the NBs, such as venous expansion with physiological serum $(\mathrm{p}=0.51)$, metabolic acidosis $(\mathrm{p}=0.15)$, the use of bicarbonate $(\mathrm{p}=0.64)$, amines $(\mathrm{p}=0.50$ for dobutamine, $\mathrm{p}=1.00$ for dopamine), and midazolam ( $\mathrm{p}=0.20$ for bolus), did not significantly differ between groups. No PTI received continuous midazolam, and surfactant therapy occurred within two hours after birth.

\section{Discussion}

The between-group comparison of the number of adverse events during the 72 hours after surfactant therapy did not reveal any significant differences. This finding indicates that maintaining the PTIs without changing their position (the head placed in the midline with a headboard inclined at 30 degrees) and applying the multidisciplinary team care procedures (i.e., minimal handling) based on their needs did not significantly affect $\mathrm{HR}, \mathrm{SpO}_{2}$, or body temperature. However, the occurrence of peripheral oxygen desaturation was related to the type of procedure (e.g., physicians, generally invasive, and endotracheal tube suction procedures); specifically, more types of procedures positively predicted the number of desaturation events. These results match those of studies showing a higher incidence of peripheral oxygen desaturation events and hypoxemia among PTIs receiving endotracheal tube suction procedures ${ }^{12,20-23}$ and decubitus changing, respectively. These results were significant different from other types of procedures ${ }^{20-23}$.

Endotracheal suctioning, which is commonly performed by physical therapists in the NICU, is an invasive procedure with the potential to generate significant clinical instability among PTIs ${ }^{24,25}$. Therefore, this procedure must be indicated and executed properly to prevent adverse events related to oxygenation, airway lesions, laryngospasm, bradycardia, atelectasis, pain, increased intracranial pressure, local infection, and pneumothorax ${ }^{24,25}$.

Although it was not the primary objective of the current study, the occurrence of PIVH significant differed between the minimal handling protocol groups 72 hours after surfactant therapy: All PTIs who exhibited this change were assigned to the SG (i.e., they stayed under minimal handling conditions for 12 hours). Because minimal handling time differentiated the two groups, this finding indicates that minimal handling time affects the development of this change during the first 72 hours after surfactant therapy. This period is critical for the occurrence of such a change ${ }^{14,15}$.

McLendon et al. ${ }^{16}$ conducted a multicenter observational study of five NICUs in the United States to evaluate the most effective healthcare practices for reducing brain injuries (e.g., PIVH) among very low birth weight NBs on MV during the first week of life, especially during the first 72 hours. This study demonstrated that, among other care measures, the practice of minimal handling by maintaining the head in the midline, avoiding endotracheal suction, maintaining cardiorespiratory stability after exogenous surfactant therapy, reducing

Table 1. Baseline characteristics of the preterm infants according Gestacional Age and Weight at birth, Apgar 1' and Apgar 5' by type of minimal handling group.

\begin{tabular}{cccc}
\hline & \multicolumn{2}{c}{ Groups } & \\
Variable & SG $(\mathbf{n = 2 2})$ & MG (n=18) & $p$ Value \\
Gestacional Age at birth (wk) & $30.0(28.0$ to 31.0$)$ & $29.0(28.0$ to 30.4$)$ & 0.40 \\
Birth Weight (g) & $1058(870$ to 1341$)$ & $1030(916$ to 1212$)$ & 0.58 \\
Apgar 1' & $8.0(7.0$ to 8.0$)$ & $7.0(6.0$ to 8.0$)$ & 0.20 \\
Apgar 5 & $9.0(8.0$ to 9.0$)$ & $8.5(8.0$ to 9.0$)$ & 0.44 \\
\hline
\end{tabular}

Data shown as median. Confidence Interval=95\%. Mann-Whitney Test. SG= Standard Grupo; MG=Modified Group. 
Table 2. Baseline characteristics of the preterm infants according Gender, Size, Antenatal Corticosteroides and Hyaline Membrane Disease Classification by minimal handling group.

\begin{tabular}{|c|c|c|c|c|c|}
\hline \multirow{2}{*}{ Characteristics } & & \multicolumn{2}{|c|}{ Group } & \multirow[b]{2}{*}{ Total $(n=40)$} & \multirow[b]{2}{*}{$p$ Value } \\
\hline & & SG $(n=22)$ & $\operatorname{MG}(n=18)$ & & \\
\hline \multirow{2}{*}{ Gender } & Female & $10(45.5 \%)$ & $13(72.2 \%)$ & $23(57.5 \%)$ & \multirow{2}{*}{0.12} \\
\hline & Male & $12(54.5 \%)$ & $5(27.8 \%)$ & $17(42.5 \%)$ & \\
\hline \multirow{2}{*}{${ }^{\dagger}$ Size } & AGA & $12(54.5 \%)$ & $11(61.1 \%)$ & $23(57.5 \%)$ & \multirow{2}{*}{0.76} \\
\hline & SGA & $10(45.5 \%)$ & $7(38.9 \%)$ & $17(42.5 \%)$ & \\
\hline \multirow{2}{*}{ Antenatal Corticosteroides } & No & $6(27.3 \%)$ & $3(16.7 \%)$ & $9(22.5 \%)$ & \multirow{2}{*}{0.48} \\
\hline & Yes & $16(72.7 \%)$ & $15(83.3 \%)$ & $31(77.5 \%)$ & \\
\hline \multirow{3}{*}{$\begin{array}{l}\text { Hyaline Membrane Disease } \\
\text { Classification }\end{array}$} & Mild & $10(45.5 \%)$ & $5(27.8 \%)$ & $15(37.5 \%)$ & \multirow{3}{*}{0.46} \\
\hline & Moderate & $9(40.9 \%)$ & $11(61.1 \%)$ & $20(50 \%)$ & \\
\hline & Severe & $3(13.6 \%)$ & $2(11.1 \%)$ & $5(12.5 \%)$ & \\
\hline
\end{tabular}

Data shown as number of cases (\%). Fisher's Exact Test. SG=Standard Group; MG=Modified Group. Size according gestacional age of the preterm infant. AGA: Appropriate for Gestacional Age; SGA: Small for Gestacional Age

Table 3. Comparison of adverse events in baseline (first 12 hours after surfactant) and 12 to 72 hours after surfactant by minimal handling group.

\begin{tabular}{lcccccc}
\hline & & Baseline & & \multicolumn{2}{c}{ Between 12 hours to 72 hours after surfactant } \\
& SG & MG & $p$ Value & SG & MG & $p$ Value \\
Bradycardia(n) & 1.0 & 2.0 & 0.18 & 8.5 & 12.0 & 0.90 \\
Tachycardia(n) & 0.0 & 0.0 & 0.68 & 7.0 & 8.0 & 0.70 \\
Hypothermia(n) & 3.0 & 2.5 & 0.70 & 13.0 & 12.0 & 0.60 \\
Hyperthermia(n) & 0.0 & 0.0 & 0.70 & 1.0 & 1.0 & 0.90 \\
Dessaturação(n) & 0.0 & 2.0 & 0.10 & 8.0 & 7.5 & 0.90 \\
\hline
\end{tabular}

Mann-Whitney Test for comparison of median of independent groups. SG=Standard Group; MG=Modified Group; (n) = number of events.

stress caused by noise and light, and reducing painful procedures reduced the occurrence of PIVH in this population.

As stated previously, this study sought to evaluate the physiological effects due to minimal handling protocols, which are inexpensive and available at all Brazilian NICUs, and not the incidence of PIVH. Thus, our findings confirm and complement those reported by McLendon et al. ${ }^{16}$ because they demonstrate that one of the benefits of minimal handling among very low birth weight NBs is ensuring the stability of their physiological parameters.

The literature shows that very low birth weight PTIs are at a 50\% risk of developing PIVH during the first 24 hours of life; furthermore, this risk increases to $90 \%$ over the next 72 hours $^{26}$. Thus, given the likelihood of the increased occurrence of this change over the first days of life $^{16}$ and the fact that PIVH can lead to delays in psychomotor development with possible sequelae ${ }^{27}$, NICU professionals should consider the types of procedures and their periodicity with regard to PTIs undergoing surfactant therapy, especially over the first 72 hours of life.

Studies examining the effect of minimal handling protocols on the physiological stability and development of PTIs admitted to NICUs should evaluate the protocols used within these units, given the effects of the various factors involved in this context, especially with regard to the occurrence of PIVH, which needs to be investigated further.

The present study is important because it is the first Brazilian study to explore matters that have been rarely investigated, but which are of fundamental importance to clinical practice. This study compared two minimal handling protocols on the $\mathrm{HR}, \mathrm{SpO}_{2}$, and body temperature of PTIs with RDS receiving MV and exogenous surfactant therapy in accordance with the literature. However, this study has limitations such as its small sample size, the lack of evaluation regarding the effect of sound stimuli 

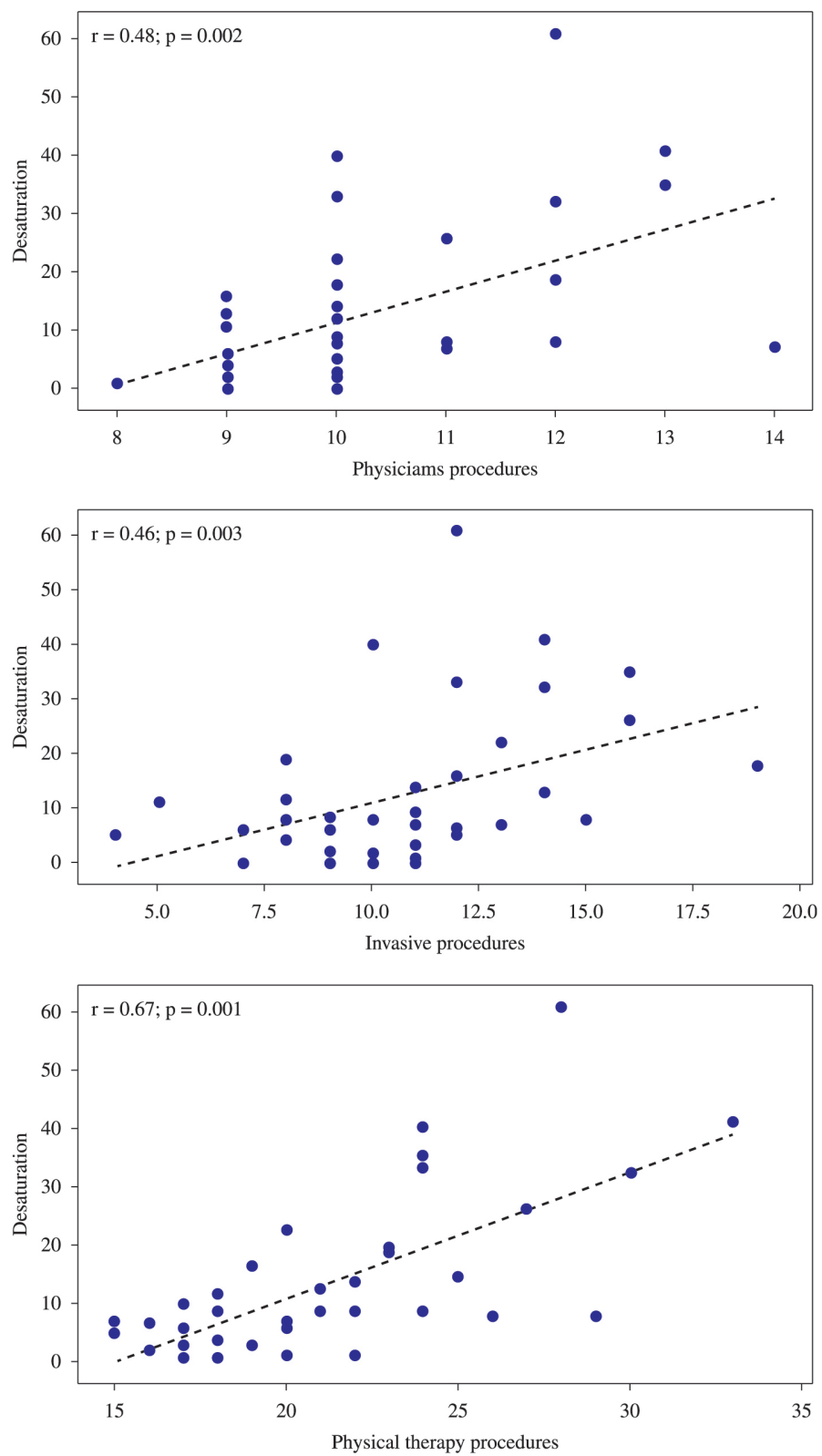

Figure 2. The correlations between the number of oxygen desaturation events and physician procedures, invasive procedures, and physical therapy procedures.

and pain in arterial blood pressure, the effect of the MV parameters, the duration of adverse events, and NBs' behavioral states during the intervention and their duration.

Despite these limitations, the results enable us to recommend the minimal handling protocol in clinical practice among PTIs receiving MV and exogenous surfactant therapy over the first 72 hours of life because this protocol is safe. However, this recommendation must be applied with caution because peculiarities and other factors associated with the healthcare conducted in different NICUs across Brazil might exist that also affect the clinical stability of NBs. These peculiarities might include the profile and adherence of the multidisciplinary team with regard to changes in neonatal care routines as well as the perceptions of healthcare professionals concerning the practice of minimal handling among PTIs $^{8}$. These factors must be investigated further.

The findings of this study can effectively contribute to the roles played by NICU multidisciplinary teams, especially those of the physical therapist, 
in evaluating and intervening with defined criteria based on scientific evidence. However, physical therapy techniques and procedures must be studied further in this context. Because physical therapists have been gaining autonomy and appreciation for their activities and work within these units, studies in neonatology should facilitate the production of scientific knowledge regarding physical therapy and the use of evidence-based practice in clinical decision making.

In conclusion, the practice of minimal handling as performed in this study did not alter the physiological stability of very low birth weight NBs. However, additional studies are needed to primarily investigate the occurrence of PIVH, especially within the first 72 hours after birth.

\section{- Acknowledgments}

The professionals of the "Incubadora da Integralidade" (Comprehensive Health Incubator) Inter-institutional Technical and Scientific Development Program and the multidisciplinary team of the NICU at Sofia Feldman Hospital for their collaboration and support.

\section{References}

1. Bancalari E. Changes in the pathogenesis and prevention of chronic lung disease of prematurity. Am J Perinatol. 2001;18:1-9. PMid:11321240. http://dx.doi. org/10.1055/s-2001-12940

2. Jobe AH, Ikegami M. Lung development and function in preterm infants in the surfactant treatment era. An Rev Physiol. 2000;62:825-46. PMid:10845113. http://dx.doi. org/10.1146/annurev.physiol.62.1.825

3. World Health Organization. Low Birthweight- Cowntry, regional and global estimates. WHO Publications; 2004. [cited 2009 Apr 6]. Available from: www.who.int.

4. Fanaroff AA, Hack M, Walsh MC. The NICHD neonatal research network: changes in practice and outcomes during the first 15 years. Sem Perinatol. 2003;27:2817. PMid:14510318. http://dx.doi.org/10.1016/ S0146-0005(03)00055-7

5. Aylward GP. Neurodevelopmental outcomes of infants born prematurely. J Dev Behav Ped. 2005;26:427-40. PMid:16344661. http://dx.doi. org/10.1097/00004703-200512000-00008

6. Collaborative European Multicenter Study Group. Surfactant replacement therapy for severe neonatal respiratory distress syndrome: an international randomized clinical trial. Pediatrics. 1988;82(5):683-91. PMid:2903480.
7. Sweet DG, Halliday HL. The use of surfactants in 2009 . Arch Dis Child. 2009;94:78-83. PMid:19460896. http:// dx.doi.org/10.1136/adc.2008.153023

8. Peters KL. Infant handling in the NICU: does developmental care make a difference? An evaluative review of the literature. J Ped Nurs. 1999;13(3):83-109. PMid:10818863.

9. Als H, Lawhon G, Duffy FH, McAnulty GB, GibesGrossman GB, Blickman JG.Individualized development care for the very low birth weight preterm infant: medical and neurofunctional effects. JAMA. 1994;272(11):853-8. PMid:8078162. http://dx.doi. org/10.1001/jama.1994.03520110033025

10. Bell AH, Skov L, Lundstrom KE, Saugstad OD, GReisen G. Cerebral blood flow and plasma hypoxanthine in relation to surfactant treatment. Acta Paediatr. 1994;83:910-4. PMid:7819684. http://dx.doi. org/10.1111/j.1651-2227.1994.tb13169.x

11. Vandenberg KA. Individualized developmental care for high risk newborn in the NICU: a practice guideline. Early Hum Devel. 2007;83:433-42. PMid:17467932. http:// dx.doi.org/10.1016/j.earlhumdev.2007.03.008

12. Murdoch DR, Darlow BA. Handling during neonatal intensive care. Arch Dis Child. 1984;59:957-61. PMid:6497433. http://dx.doi.org/10.1136/adc.59.10.957

13. Miller DB, Holditch-Davis D. Interactions of parents and nurses with highrisk preterm infants. Res Nur Health. 1992;15:187-97. PMid:1509112. http://dx.doi. org/10.1002/nur.4770150305

14. Volmer B, Roth S, Baudin J, Stewart AL, Neville B, Wyatt J. Predictors of long-term outcome in very preterm infants:gestational age versus neonatal cranial ultrasound. Pediatrics. 2003;112:1108-14. PMid:14595054. http:// dx.doi.org/10.1542/peds.112.5.1108

15. Werner NP, Conway AE. Caregiver contacts experienced by premature infants in the neonatal intensive care unit. Am J Mat Child Nurs. 1990;19:21-43. PMid:2134777.

16. McLendon D, Chek J, Carteaux P, Michael L, Moehring J, Secrest JW, et al. Implementation of potentially better practices for the prevention of brain hemorrhage and ischemic brain injury in very low birth weight infants. Pediatrics. 2003;111(4):e497-503. PMid:12671170.

17. Sweet DG, Carnielli V, Greisen G, Hallman M, Ozek E, Plavka R, et al. European consensus guidelines on management of neonatal respiratory distress syndrome. Neonatology. 2010;97:402-17. PMid:20551710. http:// dx.doi.org/10.1159/000297773

18. Lowe MCJr, Woolridge DP. The Normal Newborn Exam, or Is It? Emerg Med Clin North Am. 2007;25:92146. PMid:17950130. http://dx.doi.org/10.1016/j. emc.2007.07.013

19. Papile L, Burstein J, Burstein R. Incidence and evolution subependymal and intraventricular hemorrhage: A study of infants with birth weights less than $1500 \mathrm{gm}$. J Ped. 1978;92(4):529-34. PMid:305471. http://dx.doi. org/10.1016/S0022-3476(78)80282-0

20. Speidel BD. Adverse effects of routine procedure on preterm infants. Lancet. 1978;22(1):864-6. PMid:76807. http://dx.doi.org/10.1016/S0140-6736(78)90204-0 
21. Norris S, Campbell L, Brenkert S. Nursing procedures and alterations in transcutaneous oxygen tension in preterm infants. Nurs Res. 1982;31:330-6. PMid:6924215. http:// dx.doi.org/10.1097/00006199-198211000-00003

22. Dandford DA, Miske S, Headley J, Nelson RM. Effects of routine care procedures on transcutaneous oxygen in neonates: a quanitative approach. Arch Dis Child. 1983;58:20-3. PMid:6830270. http://dx.doi.org/10.1136/ $\operatorname{adc} .58 .1 .20$

23. Evans JC. Incidence of hypoxemia associated with caregiving in premature infants. Neo Net. 1991;10:17-24. PMid: 1886555 .

24. Nicolau CM, Falcão MC. Effects of chest physiotherapy in newborns: a critical review of the literature. Rev Paul Pediatr. 2007;25:72-5.

25. Nicolau CM. Avaliação da dor em recém-nascidos prematuros durante a fisioterapia respiratória. Rev Bras Saúde Matern Infant. 2008;8:285-90. http://dx.doi. org/10.1590/S1519-38292008000300007

26. Linder N, Haskin O, Levit O, Klinger G, Prince T, Naor $\mathrm{N}$, et al. Risk Factors for Intraventricular Hemorrhage in
Very Low Birth Weight Premature Infants: A Retrospective Case-Control Study. Pediatrics. 2003;111(5):590-5. http:// dx.doi.org/10.1542/peds.111.5.e590

27. O'Shea TM, Kuban KC, Allred AN, Paneth N, Pagano M, Dammann $\mathrm{O}$, et al. Neonatal cranial ultrasound lesions and developmental delays at 2 years of age among extremely low gestacional age children Pediatrics. 2008;22:e662-9. PMid:18762501 PMCid:PMC2989661. http://dx.doi. org/10.1542/peds.2008-0594

\section{Correspondence}

\section{Marcelo Velloso}

Universidade Federal de Minas Gerais Departamento de Fisioterapia

Av. Antônio Carlos, 6627 - Campus Pampulha CEP 31270-901, Belo Horizonte, MG, Brazil

e-mail: marcello.vel@gmail.com 


\section{Appendix 1 - MINIMAL HANDLING PROTOCOLS \\ STANDARD MINIMAL HANDLING PROTOCOL}

(Based on the routines of the NICUs at the institution where the study was conducted)

\section{- 1 -Throughout the study period the following actions will be taken:}

-A fabric cover will be maintained over the infants' incubators to reduce the stress caused by light.

-Actions will be taken to reduce noise and the stress caused by that noise (e.g., not hitting the incubator or placing objects on top of it; opening and closing the portholes of the incubator carefully; speaking quietly; promptly attending to monitor and crib alarms; avoiding the accumulation of water in the MV circuits, avoid conversations next to the crib, and careful garbage collection and hamper use).

-If they so desire, the infants' mothers (full time) and fathers ( 9 am to $9 \mathrm{pm})$ as well as other family members may visit them in the ICU in accordance with the visiting schedule posted on the door of each ICU and the standards of the institution (i.e., a maximum of two visitors, one at a time, for 15 minutes, and accompanied by the father or mother).

- 2 - At least 12 hours after the admission care procedure described in Chapter 2 (section 2.6, item 2.6.2), the following procedures will be performed:

-Physical and clinical evaluations (pulmonary and cardiac auscultation, arterial pulse measurement, palpation of the abdomen, visual observation of skin integrity and the infant's body as a whole) will be conducted by the physician, nurse, nursing technician, or physical therapist, preferably based on the following schedule: morning ( 8 am to $10 \mathrm{am}$ ), afternoon ( $2 \mathrm{pm}$ to $4 \mathrm{pm}$ ), and evening ( $8 \mathrm{pm}$ to $10 \mathrm{pm}$ ). Evaluations may be conducted at other times.

-The positioning of sensors (pulse oximetry and temperature) will be changed every 2 hours.

-Blood gas analysis and chest radiograph will be conducted after one hour and six hours of surfactant therapy, respectively.

-Blood pressure will measured when ordered by a physician.

-Drugs and sedation bolus will be administered via the umbilical catheter in the event of agitation, facial expressions suggestive of pain, poor adaptation to $\mathrm{MV}$, or prior to invasive procedures such as venous or arterial punctures upon medical prescription.

-Puncture is necessary to measure capillary blood glucose according to medical criteria.

-Endotracheal suction is not to be performed unless otherwise indicated through the evaluation of the respiratory pattern by the on-call physical therapist (i.e., an obstructive pattern or poor adjustment to MV associated with $\mathrm{SpO}_{2}<88 \%, \mathrm{HR}<100 \mathrm{bpm}$, or both without improvement after increasing $\mathrm{MV}\left(\mathrm{FiO}_{2}>\right.$ $50 \%$, peak inspiratory pressure $[\mathrm{PIP}] \geq 20 \mathrm{cmH}_{2} \mathrm{O}$, positive end-expiratory pressure [PEEP] $\geq 6 \mathrm{cmH}_{2} \mathrm{O}$ and respiratory rate $[\mathrm{f}] \geq 45 \mathrm{bpm}$ ) or due to medical request after infant evaluation.

-The infant will not receive baths or hygienic care

-The infant will be positioned in the bed as follows:

-supine in "nest" with fabric rolls;

-head in the midline and neutral position; and

-headboard elevated to 30 degrees.

\section{- 3 - The following procedures will be performed over the next data collection period (up to 72 hours after birth):}

-Physical and clinical evaluations (pulmonary and cardiac auscultation, arterial pulse measurement, palpation of the abdomen, visual observation of skin integrity and the infant's body as a whole) will be conducted by the physician, nurse, nursing technician, or physical therapist, preferably based on the following schedule: morning ( 8 am to $10 \mathrm{am}$ ), afternoon ( $2 \mathrm{pm}$ to $4 \mathrm{pm}$ ), and evening ( $8 \mathrm{pm}$ to $10 \mathrm{pm})$. Evaluations may be conducted at other times.

-The positioning of sensors (pulse oximetry and temperature) will be changed every 2 hours.

-Incubator bed sheets and diapers change will be routinely changed every 2 hours.

-Arterial or venous puncture for blood gas analysis and lumbar puncture for other exams will be performed according to medical indication.

-Peripheral access will occur, if necessary, according to medical request.

-Dressings for skin lesions will be applied when necessary.

-Indwelling urinary catheter will be used in cases of distended bladder and when medically indicated. 
-Chest and abdomen radiography will be performed when medically indicated or requested.

-The endotracheal tube will be repositioned, if necessary after radiographic evaluation.

-The endotracheal tube will be replaced or fixed if it is loose, at risk of accidental extubation, or both.

-Drugs and sedation bolus will be administered via the umbilical catheter in the event of agitation, facial expressions suggestive of pain, poor adaptation to $\mathrm{MV}$, or prior to invasive procedures such as venous or arterial punctures upon medical prescription.

- Endotracheal suction is not to be performed unless otherwise indicated through the evaluation of the respiratory pattern by the on-call physical therapist (i.e., an obstructive pattern or poor adjustment to MV associated with $\mathrm{SpO}_{2}<88 \%$, $\mathrm{HR}<100 \mathrm{bpm}$, or both without improvement after increasing $\mathrm{MV}\left(\mathrm{FiO}_{2}>\right.$ $50 \%, \mathrm{PIP} \geq 20 \mathrm{cmH}_{2} \mathrm{O}, \mathrm{PEEP} \geq 6 \mathrm{cmH}_{2} \mathrm{O}$, and $\mathrm{f} \geq 45 \mathrm{bpm}$ ) or due to medical request after infant evaluation.

-Infants will be reweighed 48 hours after birth if they are stable ( $\mathrm{SpO} 2>90 \%$ and $\mathrm{HR}>100 \mathrm{bpm})$ and upon medical request.

-The infant will be bathed and receive hygienic care beginning on the second day of life, if necessary.

-The infant will be positioned in the bed as follows:

-supine in "nest" with fabric rolls;

-head in the midline and neutral position; and

-headboard elevated to 30 degrees.

-Decubitus will be adjusted every three hours.

\section{MODIFIED MINIMAL HANDLING PROTOCOL}

(Proposed by the researchers)

\section{- 1 - Throughout the study period the following actions will be taken:}

-A fabric cover will be maintained over the infants' incubators to reduce the stress caused by light.

-Continual guidance will be provided to the ICU team regarding the reduction of noise and the stress caused by that noise (e.g., not hitting the incubator or placing objects on top of it; opening and closing the portholes of the incubator carefully; speaking quietly; promptly attending to monitor and crib alarms; avoiding the accumulation of water in the MV circuits, preventing crib shifting, and careful garbage collection and hamper use).

-If they so desire, the infants' mothers (full time) and fathers ( 9 am to 9 pm) as well as other family members may visit them in the ICU in accordance with the visiting schedule posted on the door of each ICU and the standards of the institution (i.e., a maximum of two visitors, one at a time, for 15 minutes, and accompanied by the father or mother).

- 2 - At least 12 hours after the admission care procedure described in Chapter 2 (section 2.6 item

\subsection{2), the following procedures will be performed:}

-Physical and clinical evaluations (pulmonary and cardiac auscultation, arterial pulse measurement, palpation of the abdomen, visual observation of skin integrity and the infant's body as a whole) will be conducted by the physician, nurse, nursing technician, or physical therapist, preferably based on the following schedule: morning (8 am to $10 \mathrm{am})$, afternoon ( $2 \mathrm{pm}$ to $4 \mathrm{pm}$ ), and evening ( $8 \mathrm{pm}$ to $10 \mathrm{pm}$ ). When necessary (e.g., clinical instability), the evaluations may be conducted at times other than those stated above.

-The positioning of sensors (pulse oximetry and temperature) will be changed every 2 hours.

-Blood gas analysis and chest radiograph will be conducted after one hour and six hours of surfactant therapy, respectively.

-Blood pressure will measured when ordered by a physician.

-Drugs and sedation bolus will be administered via the umbilical catheter in the event of agitation, facial expressions suggestive of pain, poor adaptation to $\mathrm{MV}$, or prior to invasive procedures such as venous or arterial punctures upon medical prescription.

-Puncture is necessary to measure capillary blood glucose according to medical criteria.

-Endotracheal suction is not to be performed unless otherwise indicated through the evaluation of the respiratory pattern by the on-call physical therapist (i.e., an obstructive pattern or poor adjustment to MV associated with $\mathrm{SpO}_{2}<88 \%$, $\mathrm{HR}<100 \mathrm{bpm}$, or both without improvement after increasing $\mathrm{MV}\left(\mathrm{FiO}_{2}>\right.$ $50 \%, \mathrm{PIP} \geq 20 \mathrm{cmH}_{2} \mathrm{O}, \mathrm{PEEP} \geq 6 \mathrm{cmH}_{2} \mathrm{O}$, and $\mathrm{f} \geq 45 \mathrm{bpm}$ ) or due to medical request after infant evaluation.

-The infant will not receive baths or hygienic care

-The infant will be positioned in the bed as follows: 
-supine in "nest" with fabric rolls;

-head in the midline and neutral position; and

-headboard elevated to 30 degrees.

\section{- 3 - The following procedures will be performed over the next data collection period (up to 72 hours after birth):}

-Physical and clinical evaluations (pulmonary and cardiac auscultation, arterial pulse measurement, palpation of the abdomen, visual observation of skin integrity and the infant's body as a whole) will be conducted by the physician, nurse, nursing technician, or physical therapist, preferably based on the following schedule: morning ( 8 am to $10 \mathrm{am})$, afternoon ( $2 \mathrm{pm}$ to $4 \mathrm{pm})$, and evening ( $8 \mathrm{pm}$ to $10 \mathrm{pm})$. Evaluations may be conducted at other times.

-The positioning of sensors (pulse oximetry and temperature) will be changed every 2 hours.

-Diapers will be changed when needed or impairing infants' physical and clinical conditions.

-Arterial or venous puncture for blood gas analysis and lumbar puncture for other exams will be performed according to medical indication.

-Peripheral access will occur, if necessary, according to medical request.

-Dressings for skin lesions will be applied when necessary.

-Indwelling urinary catheter will be used in cases of distended bladder and when medically indicated.

-Chest and abdomen radiography will be performed when medically indicated or requested.

-The endotracheal tube will be repositioned, if necessary after radiographic evaluation.

-The endotracheal tube will be replaced or fixed if it is loose, at risk of accidental extubation, or both.

-Drugs and sedation bolus will be administered via the umbilical catheter in the event of agitation, facial expressions suggestive of pain, poor adaptation to $\mathrm{MV}$, or prior to invasive procedures such as venous or arterial punctures upon medical prescription.

-Endotracheal suction is not to be performed unless otherwise indicated through the evaluation of the respiratory pattern by the on-call physical therapist (i.e., an obstructive pattern or poor adjustment to MV associated with $\mathrm{SpO}_{2}<88 \%$, HR $<100 \mathrm{bpm}$, or both without improvement after increasing $\mathrm{MV}\left(\mathrm{FiO}_{2}>\right.$ $50 \%$, PIP $\geq 20 \mathrm{cmH}_{2} \mathrm{O}$, PEEP $\geq 6 \mathrm{cmH}_{2} \mathrm{O}$, and $\mathrm{f} \geq 45 \mathrm{bpm}$ ) or due to medical request after infant evaluation.

-The infant will not receive baths, cleanings, or a change of sheets, nor will they be weighed.

-The infant will be positioned in the bed as follows:

-supine in "nest" with fabric rolls;

-head in the midline and neutral position; and

-headboard elevated to 30 degrees. 


\section{Team training}

Appendix 2 - Experimental protocol for fidelity analysis

The same researcher trained the 137 professionals of the NICU at the institution where this study was conducted before the study began. This training was conducted for one month during all shifts (morning, afternoon, and evening) for 30 to 40 minutes, either individually or in pairs. The goal of the training was to familiarize the professionals with the experimental protocol, thereby qualifying them to execute the study and become a team member. During training, an explanation was provided regarding completing the data collection form to ensure consistency of data analysis. The professionals were also interviewed to document the team's qualifications, issues regarding their professional category, duration of training in the area, and experience working in the NICU.

Communication with the team

Red plates were fixed to the incubators to identify the modified minimal handling protocol group ( 72 hours), and blue plates were used to identify the standard minimal handling protocol group (12 hours). These plates informed the NICU professionals of the care procedures needed to be conducted for each NB. The monitors used for data collection were standardized and identified by placing stickers with the name of the study so that the nursing staff could monitor the NBs during admission and throughout the study.

\section{Protocol manual}

To guarantee the quality of the care provided by the NICU multidisciplinary team with regard to the PTIs participating in the primary study, the minimal handling protocols (standard and modified) were printed and placed with the NBs' medical records. This procedure facilitated consultation in the event of team member doubt. The printed material described the schedules and procedures as well as the terms "standard minimal handling" protocol (12 hours), which the institution where the study was conducted used to refer to the protocol, and "modified minimal handling protocol" ( 72 hours), which referred to the proposed and tested study procedure. Throughout the study, the researcher who conducted the team training clarified doubts and consolidated the protocol guidelines.

\section{Procedure registration form}

The multidisciplinary team of the NICU where the study took place received training with regard to how to complete the registration forms. Every professional marked an " $\mathrm{X}$ " in front of the procedure performed for the NB as well as the shift and the day. For each shift that day, specific colors were standardized to complete the form: Blue denoted the morning shift, black represented the afternoon shift, and red denoted the night shift. This standardization enabled the identification of the number of procedures performed and the adverse events that occurred during different shifts. The researcher responsible for training the team checked the registration forms for completion throughout the course of data collection.

\section{Protocol differentiation}

The PTIs receiving the standard minimal handling protocol were maintained under the following conditions during their first 12 hours of life: supine position with a headboard inclined to 30 degrees; head in midline and in neutral position; and no bed sheet changes. The evaluations and procedures performed by the physicians, nurses, nursing technicians, and physical therapists were conducted according to the NBs' needs. Between the first 12 hours and 72 hours of life, the NBs in this group underwent the following procedures: decubitus change (dorsal, ventral, and lateral) every three hours, and sheets changed every 12 hours. Physicians, nurses, nursing technicians, and physical therapists performed the evaluations and procedures according to Sofia Feldman Hospital's protocols.

The PTIs receiving the modified minimal handling protocol were maintained during their first 72 hours of life in the following conditions: supine position and headboard inclined to 30 degrees; head in midline and in neutral position; and no bed sheet change. The physicians, nurses, nursing technicians, and physical therapists performed the evaluations and procedures according to the needs of the PTIs.

\section{Environment}

The study took place in the NICUs of the hospitals. In these NICUs, fabric covers were used on the NB incubators to avoid the adverse effects of exposure to light. No control measures were performed with regard to the noise present in these units. 